\section{KẾT LUẬN}

HXTĐT với Capecitabine trước phẫu thuât là phương pháp điêu trị hiệu quả. Tỷ lệ đáp ứng toàn bộ sau điều trị đạt 83,4\%, tỷ lệ BN được PT triệt căn là $100 \%$ trong đó có $85,4 \%$ BN được PT bảo tôn cơ thắt hậu môn. Điều trị HXTĐT tiển phẫu cho bệnh nhân UTTT giai đoạn II, III là phương pháp điều trị an toàn và ít độc tính.

\section{TÀI LIÊU THAM KHẢO}

1. International Agency for Research on Cancer (2020), Globocan 2020: Estimated Cancer Incidence, Mortality and Prevalence Worldwide in 2020.

2. NCCN (2019), Rectal Cancer, Clinical Practice Guidelines in Oncology.

3. Kinjal Parikh, Albert S. DeNittis, Gerald Marks et al., (2019), "Neoadjuvant chemotherapy and high-dose radiation using intensity-modulated radiotherapy followed by rectal sparing TEM for distal rectal cancer", Journal of Radiation Oncology, 8(2), pp. 217-224.

4. William Chapman, Hyun Kim, Philip Bauer et al., (2019), "Total neoadjuvant therapy with short course radiation compared to concurrent chemoradiation in rectal cancer", Journal of Clinical Oncology, 37(4_suppl), pp. 468-486.

5. Pham Cẩm Phương (2013), Đánh giá hiệu quả hoá xạ trị kết hợp Capecitabine trưỡc mổ trong ung thư trực tràng thấp tiến triển tại chố, Luận văn Tiến sĩ y hợc, Chuyên ngành ung thư', Đại học Y Hà Nội.

6. Nguyễn Văn Hiếu, Lê Văn Quảng, Bùi Cổng Toàn et al., (2018), "Đánh giá kết quả hóa xạ trị tiền phẩu trong ung thư trực tràng giai đoạn xâm lấn", Tạp chí khoa học công nghệ Việt Nam, 60(2), pp. 1-4.

7. de Bruin AF, Nuyttens JJ, Ferenschild FT et al., (2008), "Preoperative chemoradiation with capecitabine in locally advanced rectal cancer", Neth J Med, 66(2), pp. 71-76.

8. Nguyễn Xuân Kiên, Nguyễn Đình Châu, Nguyê̂n Thị Hà et al., (2017), "Đánh giá kết quá điểu tri hóa xa tri tiền phấu với capecitabine ở bệnh nhân ung thư trực tràng giai đoạn tiến triển còn khả năng phâuu thuât tai Bênh viên Trung ương Quân đội 108", Tạp chí Ỳ dược lẩm sàng 108, 12(9), pp. 135-140.

\title{
ỨNG DỤNG VẠT DA CÂN THƯỢNG ĐÒN CÓ NỐI MACH VI PHẪU TAI ĐẦU XA TRONG TA O HÌNH SẸO DI CHỨNG BỎNG VÙNG CỔ
}

\section{TÓM TẮT}

Mục tiêu: Che phủ khuyết rộng toàn bộ vùng cằm cổ, sử dung nhánh xuyên tại đầu xa của vat da cân thượng đòn nhằm tăng kích thước của vat là phương pháp hiệu quả, có tính ứng dụng cao. Đối tượng và phương pháp: 30 bệnh nhân có sẹo co kéo nặng vùng cổ được phẩu thuât sử dung vạt da cân thượng đòn có nối vi phẫu tai đầu xa từ năm 2014 đến 2020. Vạt được nối vi phẫu tại đâu xa sử dụng nhánh xuyên của động mach cùng vai ngực sau khi phấu tích vạt nâng vạt. Kết quả: Toàn bộ 30 vạt da sống hoàn toàn, chiều dài vạt đat tối đa $28 \mathrm{~cm}$ và chiều rộng tối đa $25 \mathrm{~cm}$. Theo dõi ở thời điểm 3 tháng sau mổ có $29 / 30$ bệnh nhân $(96,67 \%)$ hài lòng với kết quả sau mổ. Đánh giá ở thời điểm sau mổ 6 tháng, tất cả các bệnh nhân đều hài lòng với kết quả phẫu thuật. Kết luâan: Vạt da cân thượng đòn có nối mạch vi phẩu tai đâu xa là lựa chọn tối ưu trong tao hình các tổn khuyết rộng vùng cổ, đặc biệt là tạo hình sẹo di chứng bỏng.

Tự khóa: Vạt da cân thượng đòn, vạt có nối mạch vi phẩu tại đầu xa

\section{SUMMARY}

*Bệnh viện Bỏng Quốc gia Lê Hữu Trác Chịu trách nhiệm chính: Tống Thanh Hải Email: drtonghai@gmail.com Ngày nhận bài: 25/2/2021 Ngày phản biện khoa học: 12/3/2021 Ngày duyệt bài: 1/4/2021

\section{EXPANDING THE DIMENSIONS OF FLAP, SUPERCHARGING AT DISTAL PART OF FLAP WAS THE NEW POWERFUL PROCEDURE}

Purpose: To expand the dimension of flap, supercharging at distal part of flap was the new powerful procedure. Subjects and methods: 30 patients suffered from severe contructure scar in neck region were operated by using supercharged supraclavicular flap between 2014 and 2020. The thoracoacromial vessel was choiced to anatomosis at distal part after flap elevation. Results: All of flaps were survived completely, the maximum dimension of flap was $28 \mathrm{~cm}$ in length and $25 \mathrm{~cm}$ in width. Following up at 3 months postoperation, twenty-nine of the 30 patients were satisfied with both the functional and aesthetic results. All patients were satisfiedat 6 months after surgery. Conclusion: The supercharged supraclavicular flap was the optimized choice to reconstruct of neck region, especiallyfor severe defects after burn.

Keyword: supraclavicular flap, supercharged supraclavicular flap

\section{I. ĐĂT VẤN ĐỀ}

Vùng cổ là vùng có biên độ vận động rất lớn theo nhiều hướng khác nhau. Chính vì vậy, sau phẫu thuật chỉnh sửa sẹo, nguy cơ co kéo dễ có xu hướng tái phát. Thêm nữa, vùng cổ không chỉ là một vùng cần đảm bảo về chức năng mà còn rất quan trọng về mặt thẩm mỹ. Các vạt da lân cận vùng cổ luôn là lựa chọn được ưu tiên hàng 
đầu do sự lân cận về vị trí. Tuy vậy, hạn chế của các loại vạt này kích thước của vạt da còn hạn chế do phụ thuộc vào vùng cấp máu của vạt nển chưa thể đáp ứng được những tổn khuyết rộng hết cả 1 đơn vị thẩm mỹ vùng cằm cổ[1].

Vạt da cần thượng đòn dạng trục của Lamberty (1979) mặc dù được nghiên cứu từ lâu nhưng phải đến những năm gần đây mới thực sự được ứng dụng trên lâm sàng. Dạng vạt này đã góp phần giải quyết được nhiều hạn chế của nhiều phương pháp tạo hình khác, phẩn nào đáp ứng được yêu câuu tạo hình vùng cằm cổ đặc biệt là yêu cầu thẩm mỹ bởi nó mang lại chất liệu mỏng, hòa đồng với da lành lân cận vùng cằm cổ[2], [3]. Để đáp ứng yêu cầu che phủ khuyết rộng toàn bộ vùng cằm cổ, sử dụng nhánh xuyên tại đâu xa của vạt da cân thượng đòn nhằm tăng kích thước của vạt là phương pháp hiệu quả, có tính ứng dụng cao.

\section{II. ĐỐI TƯợNG VÀ PHƯƠNG PHÁP NGHIÊN CỨU}

2.1. Đối tượng nghiên cứu. 30 bệnh nhân bị sẹo co kéo vùng cổ được phẫu thuật sử dụng vạt da cân thượng đòn có nối mạch vi phẫu tại đầu xa từ tháng 9/2014 đến tháng 7/2020 tại trung tâm phẫu thuật tạo hình, thẩm mỹ và tái tạo, bệnh viện Bỏng Quổc gia Lê Hữu Trác.

Cắt sẹo, giải phóng co kéo vùng cằm cổ, xác định nguồn mạch nhận. Tiến hành cắt bỏ tổ chức sẹo vùng cằm cổ đển mô lành, cầm máu kỹ bằng đốt điện, bóc tách giải phóng các mép da để giúp giải phóng co kéo vùng cố và các cơ quan.Xác định bó mạch mặt nằm dưới lớp cơ bám da cổ, bóc tách cuống mạch và đánh dấu để tránh nhầm lẫn động mạch và tĩnh mạch.

Thiết kế vạt da cân thượng đòn có nối vi phẫu tại đâu xa. Sau khi cắt bỏ tổ chức sẹo vùng cẳm cổ và giải phóng tối đa để khôi phục lại biên độ vận động của cổ, giải phóng co kéo các cơ quan. Chúng tôi tiến hành xác định lại hình dạng và kích thước của tổn khuyết bằng cách sử dụng một miếng gạc vô trùng, cắt theo hình dáng của tổn khuyết, đánh dấu vi trí mạch nhận bằng bút màu.

Sử dụng siêu âm Doppler cầm tay xác định vị trí của cuống mạch thượng đòn và động mạch vùng vai ngực, vẽ thiết kế vạt căn cứ vào hình dạng tổn khuyết đã được xác định trước đó.

Kỹ thuật phẫu tích vạt và cuống mạch. Rạch da theo đường vẽ bờ trước của vạt tại vị trí nhánh xuyên của động mạch cùng vai. Bóc tách vạt da theo đến lớp cân, phẫu tích tìm nhánh xuyên theo định hướng của Doppler. Phẫu tích nhánh xuyên theo đường đi chếch xuống dưới, vào trong đến nguyên ủy là động mạch cùng vai. Đánh dấu mạch tìm được bằng dây cao su mềm.

Rạch da từ đầu mút vạt, bờ trước, bờ sau của vạt theo đường vẽ. Tiếp tục bóc tách vạt đến đúng lớp cân sâu, rồi nâng vạt lên cùng với lớp cân sâu. Chú ý bảo toàn nhánh xuyên vừa tìm được. Khi bóc vạt đến gần điểm gốc mạch nuôi vạt đã được đánh dấu thì dừng lại.

Dùng dao rạch đứt nốt phẩn da còn lại ở phần đâu gần, bóc tách cân, da để kéo dài cuống vạt, làm tăng thêm độ di động của cuống, tránh căng và quá xoắn vặn khi xoay vạt che phủ tổn khuyết. Tốt nhất nên giữ lại lớp cẩn, mõ quanh cuống mạch để bảo vệ nó được tốt hơn. Vùng cho vạt được ghép da mỏng hoặc khâu kín nếu có thể.

Tiến hành chuyển vạt che phủ tổn khuyết, việc khâu nối mạch máu được tiến hành dưới kính hiển vi.

Đánh giá kết quả. Kết quả sau mổ được đánh giá dựa trên tình trạng sống của vạt, tình trạng vùng cho vạt, tình trạng liên vết thương cũng như khả năng hồi phục về chức năng và thẩm mỹ. Kết quả được chia thành các mức độ: tốt, trung bình, kém và đánh giá trong 2 giai đoạn là 3 tháng sau mổ (kết quả gần) và sau 6 tháng (kết quả xa).

\section{KẾT QUẢ NGHIÊN CỨU}

30 bệnh nhân (21 nữ và 9 nam)với sẹo co kéo nặng vùng cổ được phẫu thuật sử dụng vạt da cân thượng đòn có nối mạch vi phẫu tại đầu xa. Nguyên nhân gây sẹo là do bỏng nhiệt khô $(90 \%)$, điện $(6,67 \%)$ và hóa chất $(3,33 \%)$. Vạt thu được có thể có chiều dài tối đa là $28 \mathrm{~cm}$, chiều rộng tối đa là $25 \mathrm{~cm}$ (chiều dài trung bình là $20,67 \mathrm{~cm}$, chiểu rộng trung bình của vạt là $17,5 \mathrm{~cm})$. Tất cả các bệnh nhân đều phải tiến hành ghép da mỏng tự thân tại vùng cho vạt.

30 vạt sau mổ sống hoàn toàn, vết mổ liền kỳ đầu có29/30 bệnh nhân hài lòng với kết quả sau mổ ở thời điểm 3 tháng sau mổ. Theo dõi các thời điểm 6 tháng và 1 năm sau mổ, các bệnh nhân đều hài lòng với kết quả phẫu thuật.Vùng cho vạt không xảy ra tình trạng hạn chế chức năng và các bệnh nhân đều hài lò̀ng với tình trạng sẹo tại vùng cho vạt.

Bảng 1: Các thông số vạt da cân thượng đòn có nối mạch vi phẫu tại đầu xa

\begin{tabular}{|c|c|c|c|}
\hline Các thông số & \multicolumn{3}{|c|}{ Trị giá } \\
\cline { 2 - 4 } nghiên cứu & $\begin{array}{c}\text { Trung } \\
\text { bình }\end{array}$ & $\begin{array}{c}\text { Tốí } \\
\text { thiểu }\end{array}$ & Tối đa \\
\hline Chiều dài vạt $(\mathrm{cm})$ & 20,67 & 13 & 28 \\
\hline Chiều rộng vạt $(\mathrm{cm})$ & 17,5 & 14 & 25 \\
\hline
\end{tabular}




\begin{tabular}{|c|c|c|c|c|c|c|}
\hline \multicolumn{5}{|c|}{ Tình trạng vạt } & \begin{tabular}{|c|} 
Số \\
lương
\end{tabular} & $\begin{array}{c}\text { Tỉ lệ } \\
\text { \% }\end{array}$ \\
\hline \multicolumn{5}{|c|}{$\begin{array}{c}\text { Vạt sống hoàn toàn, vết mố liên } \\
\text { kỳ đâu }\end{array}$} & 30 & 100 \\
\hline \multicolumn{5}{|c|}{$\begin{array}{l}\text { Vạt bị thiếu dưỡng, hoại tử mép } \\
\text { vạt, hoại tứ <1/3 diện tích vạt }\end{array}$} & 0 & 0 \\
\hline \multicolumn{5}{|c|}{$\begin{array}{c}\begin{array}{c}\text { Vạt hoại tử > 1/3 diền tích đến } \\
\text { toàn bộ vạt }\end{array} \\
\end{array}$} & 0 & 0 \\
\hline & & Tống & & & 30 & 100 \\
\hline \multicolumn{7}{|c|}{ Bảng 3. Tinh trạng vùng cho vạt } \\
\hline \multicolumn{2}{|c|}{ Đặc điểm } & \multicolumn{2}{|c|}{$\begin{array}{c}\text { Khâu } \\
\text { đóng trực } \\
\text { tiếp }\end{array}$} & \multicolumn{2}{|c|}{$\begin{array}{l}\text { Kết hợp ghép } \\
\text { da móng tự } \\
\text { thân }\end{array}$} & Tổng \\
\hline \multirow{3}{*}{\multicolumn{2}{|c|}{$\begin{array}{c}\text { Liền kì đầu } \\
\text { Phâu thuật } \\
\text { thì hai } \\
\text { Tống } \\
\end{array}$}} & \multicolumn{2}{|l|}{0} & \multicolumn{2}{|c|}{30} & 30 \\
\hline & & \multicolumn{2}{|l|}{0} & \multicolumn{2}{|r|}{0} & 0 \\
\hline & & \multicolumn{2}{|l|}{$\mathbf{0}$} & \multicolumn{2}{|c|}{30} & 30 \\
\hline \multicolumn{7}{|c|}{ Bảng 4. Đánh giá kêt quả sau mố } \\
\hline \multirow{2}{*}{$\begin{array}{l}\text { Kết } \\
\text { quả }\end{array}$} & \multicolumn{3}{|c|}{$\begin{array}{l}\text { Kết quả gân } \\
(n=30)\end{array}$} & \multicolumn{3}{|c|}{$\begin{array}{l}\text { Kết quả xa } \\
(n=30)\end{array}$} \\
\hline & Tốt & $\begin{array}{c}\text { Trung } \\
\text { bình }\end{array}$ & Kém & Tốt & $\begin{array}{c}\text { Trung } \\
\text { binh }\end{array}$ & Kém \\
\hline $\begin{array}{l}\text { Số } \\
\text { lượng }\end{array}$ & 29 & 1 & 0 & 30 & 0 & 0 \\
\hline Tỉ lệ o & 67 & $33 \%$ & $0 \%$ & $100 \%$ & $0 \%$ & $0 \%$ \\
\hline
\end{tabular}

Bảng 5. Nhận định chủ quan của bệnh nhân về mặt chức năng và thẩm mỹ

\begin{tabular}{|c|c|c|c|c|}
\hline $\begin{array}{c}\text { Nhận định } \\
\text { của bệnh } \\
\text { nhân }\end{array}$ & \begin{tabular}{c} 
Kết quả gần \\
\cline { 2 - 5 } \\
năng
\end{tabular} & $\begin{array}{c}\text { Thấm } \\
\text { mỹ }\end{array}$ & $\begin{array}{c}\text { Kết quả xa } \\
\text { nắng }\end{array}$ & $\begin{array}{c}\text { Thấm } \\
\text { mỹ }\end{array}$ \\
\hline Hài lòng & 30 & 29 & 30 & 30 \\
\hline Tạm chấp nhận & 0 & 1 & 0 & 0 \\
\hline Không hài lòng & 0 & 0 & 0 & 0 \\
\hline Tống & $\mathbf{3 0}$ & $\mathbf{3 0}$ & $\mathbf{3 0}$ & $\mathbf{3 0}$ \\
\hline
\end{tabular}

\section{BÀN LUÂNN}

4.1. Cơ sở giải phẫu vạt da cân thượng đòn. Năm 1979, Lamberty lần đầu tiên mổ tả mẫu vạt trục tại vùng vai dựa trên động mạch trên đòn[2]. Một nghiên cứu rõ ràng hơn về giải phẫu đã được chính tác giả công bố năm 1982, theo tác giả, vat này có một sơ đồ mạch máu nuôi dưỡng khác với các vạt khác ở vùng vai và vùng cổ sau[4]. Sau đó, có nhiều tranh cãi giữa các nhà giải phẫu và các nhà lâm sàng về sự tồn tại và cách đặt tên cho động mạch này, do nó chưa được mổ tả trong sách giáo khoa giải phẫu chung (Willam 1995). Tuy nhiên, dựa trên những mô tả trước đó của Told'ts trong " Anatomy Atlat "(1903), tác giả đã chỉ ra có một nhánh nông xuất phát từ động mạch cổ ngang vượt ra phía ngoài hố trên đòn hướng về phía mỏm cùng đòn và tận hết ở vai thì những công bố của Lamberty hoàn toàn có cơ sở khoa học và đáng tin cậy hơn nhiều khi vạt này được áp dụng thành công trên lâm sàng.Pallua và cộng sự năm 1997 đã sử dụng thành công vạt da cân thượng đòn trên 8 bểnh nhân tạo hình co kéo vùng nách[3]. Từ đó, đã có rất nhiều các tác giả khác nhau đi sâu vào nghiên cứu vạt da cân thượng đòn và sử dụng rộng rãi trên lâmm sàng.

Về cuống mạch thượng đòn:Động mạch trên đòn là nhánh nông có dạng trục cấp máu cho da, thường có nguồn gốc từ động mạch cổ ngang, trong đó, khoảng 95\% động mạch cổ ngang tách ra từ thân giáp cổ, $5 \%$ từ động mạch dưới đòn[5]. Về vị trí xuất phát, $90 \%$ động mạch dưới đòn xuất phát từ $1 / 3$ giữa xương đòn, $10 \%$ có thể xuất phát từ $1 / 3$ ngoài xương đòn[5]. Từ điểm xuất phát, nó chui lên cân, chạy trong hố trên đòn ra phía ngoài về phía khớp cùng đòn, tại đây nó phân nhánh, các nhánh này vượt ra đến phần trên ngoài của cánh tay. Theo Pallua và cộng sự (2000), động mạch này xuất phát cách 3-4 cm gốc động mạch cổ ngang, ở tất cả các trường hợp, nó được tìm thấy trong tam giác giữa bờ sau trong của cơ ức đòn chũm, tĩnh mạch cảnh ngoài và $1 / 3$ trong của xương đòn[6]. Động mạch này có đường kính 1,0$1,5 \mathrm{~mm}$ và hầu như không thay đổi trên hành trình của nó. Vũ Quang Vinh và cộng sự năm 2016 trong một nghiên cứu giải phẫu trển xác nhân thấy: động mạch trên đòn có nguyên ủy từ động mạch cổ ngang, điểm xuất phát chủ yếu nằm trong khoảng $1 / 3$ giữa xương đòn $(95 \%)$, cách đâu trong xương đòn trung bình $7,56 \mathrm{~cm}$, chiều dài của động mạch trên đòn khoảng 3,5$4,5 \mathrm{~cm}$, đường kính trung bình 1,19mm [7].

Về giới hạn và vùng cấp máu của vạt. Trong một nghiên cứu giải phâuu năm 2016, tác giả Vũ Quang Vinh và cộng sự cũng xác định các giới hạn về cấp máu của vạt da cân thượng đòn như sau: giới hạn trước cách bờ dưới xương đòn khoảng 3-4 cm, giới hạn sau là bờ trên xương bả vai, và giới hạn ngoài là cách mỏm cùng vai $2-3$ $\mathrm{cm}$. Vùng cấp máu của động mạch trên đòn đạt đượcchiều dài trung bình: $20,2 \mathrm{~cm}$, chiều rộng trung bình: 10,5cm [7].

4.2. Mở rộng kích thước vat da cân thượng đòn bằng kỹ thuật nổi mạch vi phẫu tại đâu xa

Cơ sở lý luận. Dựa vào các khái niệm về vùng giải phẫu, vùng động lực, vùng tiềm tàng mà các tác giả đã nghiên cứu, từ đó các vạt da được thiết kế đa dạng hơn và có cơ sở khoa học để đảm bảo độ an toàn cho vạt.

Vùng giải phẫu của mach máu được dưa trên quan sát về cấu trúc và được phác họa bằng độ 
rộng nơi mà nhánh của các mạch chia thành những nhánh nhỏ hơn trước khi nối thông với nhánh mạch của khu vực lân cận. Vùng giải phẫu đã được Carl Manchot mô tả vào năm 1889. Mô tả của Carl Manchot dựa trên nghiên cứu phẫu tích trên xác và kết quả đã chứng minh được vùng cấp máu cho da của các mạch chính trên cơ thể. Các nghiên cứu của Salmon sau này đã chỉ ra được sự nối thông của các mạch máu trong cơ và làm sáng tỏ chi tiết sự cấp máu cho da từ các mạch này [7].

Vùng động lực: là vùng giao thoa giữa hai vùng cấp máu lần cận nhau, khi tiến hành nâng vạt da, bóc tách tại khu vực này sẽ dẫn đến sự thay đổi áp lực trong lòng mạch và sự cân bằng động lực sẽ tạo ra sự hiệu chỉnh áp suất dòng chảy mạch máu, và thay đổi kích thước khu vực được tưới máu [8].

Vùng tiềm tàng: Được hiểu như một vùng cạnh vùng động lực và được cấp máu bởi động mạch khác và nó liên hệ với vùng giải phẫu thồng qua vùng động lực này. Để mở rộng kích thước vạt da, nói một cách khác, để dòng máu từ vùng giải phẫu qua vùng động lực đến được vùng tiêm tàng thì cần có quá trình trì hoã̃n (delay) vạt da hoặc vạt da cần được nối mạch tại đâu xa (Super charge).

Đối với vạt da cân thượng đòn, khi coi vùng cấp máu của cuống mạch thượng đòn là một vùng giải phẫu thì để mở rộng kích thước của vạt, cần phải kết nối vùng giải phẫu này với các vùng tiềm tàngđược cấp máu bằng các động mạch lân cận như động mạch cùng vai ngực, động mạch ngực ngoài, động mạch mũ cánh tay trước (sau)...

Hiệu quả. Nghiên cứu này sử dụng nhánh xuyên động mạch cùng vai ngực để tăng cường cấp máu cho đầu xa của vạt da cân thượng đòn mang lại kết quả khả quan cả về kích thước cũng như tính an toàn của vạt.

Về kích thước vạt: năm 1979, Lamberty đã áp dụng vạt da cân thượng đòn cho hai trường hợp sẹo co kéo cằm cổ thành công, với kích thước vạt khiêm tốn $16 \times 6 \mathrm{~cm}$ và $16 \times 7 \mathrm{~cm}$. Năm 1997 , Pallua thông báo sử dụng vạt thượng đòn trong điều trị 8 bệnh nhân sẹo co kéo cằm cổ với kích thước lớn nhất đạt được là $26 \times 7,5 \mathrm{~cm}$. Trần Vân Anh (2005) đã nghiên cứu ứng dụng vạt DCTÐ điều trị sẹo co kéo cằm cổ với 35 trường hợp, với kích thước vạt đạt tới $26 \times 15 \mathrm{~cm}$ [8]. Vạt da cân thượng đòn có nối mạch vi phẫu tại đầu xa trong nghiên cứu của chúng tôi đạt được chiều dài tối đa tới $28 \mathrm{~cm}$, chiều rộng tối đa tới $25 \mathrm{~cm}$. Kích thước vạt này vượt trội hơn hẳn khi so sánh với vạt da cân thượng đòn đơn thuần.

Về tính an toàn của vat: Pallua (2000) thông báo có $7,14 \%$ hoại tử đầu xa của vạt da cân thượng đòn,tuy nhiên tác giả không nều rõ diện tích hoại tử đâu xa của vạt là bao nhiêu.Trần Thiết Sơn (2004), trên 24 bệnh nhân được điều trị bằng vạt da cân thượng đòn có 3 trường hợp hoại tử toàn bộ vạt, 2 trường hợp hoại tử đâu xa [9]. Trần Vân Anh (2005) thông báo với 35 trường hợp có $1 / 35$ vạt bị hoại tử toàn bộ do yếu tố kỹ thuật khi phẫu tích, 1/35 vạt bị hoại tử đầu vạt [8]. Nghiên cứu này cho thấy $100 \%$ các trường hợp vạt sống hoàn toàn, vết mổ liền kỳ đầu. Điều này thể hiện sự ưu việt của kỹ thuật nối mạch vi phẫu tại đầu xa trong đảm bảo sự an toàn khi mở rộng kích thước của vạt da cân thượng đòn.

Về hiệu quả điều trị: Khi đánh giá kết quả điều trị ở các thời điểm 3 tháng và 6 tháng sau mổ, $100 \%$ các trường hợp đều đảm bảo các yêu cầu về chức năng, đặc biệt là khôi phục lại biên độ vận động vùng cổ. Vạt đảm bảo độ mỏng cũ̉ng như sự hòa đồng về màu sắc, cấu trúc với da lành xung quanh.

\section{3. Ưu và nhược điểm của vạt da cân thượng đò̀n có nối mạch vi phẫu tại đâu xa Ưu điểm}

- Vạt có kích thước lớn, cung cấp được diện da rộng đủ che phủ được những khuyết da có kích thước lớn toàn bộ vùng cằm cổ, đặc biệt là tái tạo theo chiều cao của vùng cổ, đảm bảo chức năng vận động vùng cổ,

- Vạt da có màu sắc tương đồng với vùng da lành vùng cổ do là da vùng vai kế cận vùng cổ nên tương đồng về độ mềm mỏng, màu sắc, tính chất da (đặc biệt là độ mỏng của vạt DCTĐ là ưu điểm lớn trong tái tạo vùng cằm cổ). Tạo được góc cằm ngay sau phẫu thuật.

- Vạt sử dụng là vạt dạng đảo, linh hoạt đồng thời tăng cường nối mạch vi phấu đầu xa có độ an toàn cao do có hai nguồn cấp máu từ hai đầu của vạt. Các mạch máu nuôi dưỡng chính cho vạt hẳng định.

Nhược điểm. Vạt có kích thước lớn nên phải ghép da nơi lấy vạt. Thẩm mỹ hạn chế để lại nơi lấy vạt. Thông thường, để có được diên da mới gần tương đồng với da vùng cằm cổ để thay thế cả khối sẹo, nhiều bệnh nhân có sẹo bỏng co kéo cằm cổ ở mức độ trung bình, nặng sẵn sàng chấp nhận với sẹo để lại vùng vai nơi cho vạt. Nhưng với những trường hợp có nhu cầu cao về mặt thẩm mỹ, đặc biệt với phụ nữ, việc chỉ định sử dụng vạt này cần cân nhắc kỹ. 


\section{KẾT LUẬN}

Vạt da cân thượng đòn có nối mạch vi phẫu tại đầu xa là lựa chọn tối ưu trong tạo hình các tổn khuyết rộng vùng cổ, đặc biệt là tạo hình sẹo di chứng bỏng. Vạt có cuống mạch được cấp máu ổn định, bóc tách an toàn; có kích thước lớn có thể che phủ được toàn bộ đơn vị thẩm mỹ vùng cổ, đảm bảo yêu cầu thẩm mỹ về độ mỏng, màu sắc hòa đồng với da lành vùng cổ.

\section{TÀI LIÊU THAM KHẢO}

1.Vinh V. Q., Ogawa R., Van Anh T.. et al (2007) Reconstruction of neck scar contractures using supraclavicular flaps: Retrospective study of 30 cases. Plastic and reconstructive surgery.119(1): 130-135.

2.Lamberty B. (1979) The supra-clavicular axial patterned flap. British journal of plastic surgery.32(3): 207-212.

3.Pallua N., Machens H.-G., Rennekampff O.. et al (1997) The fasciocutaneous supraclavicular artery island flap for releasing postburn mentosternal contractures. Plastic and reconstructive surgery.99(7): 1878-1884; discussion 1885.

4.Lamberty B. (1982) The cutaneous arterial supply of cervical skin in relation to axial skin flaps. Anatomia Clinica.3(4): 317-324.

5.Vinh V. Q., Van Anh T., Ogawa R.. et al (2009) Anatomical and clinical studies of the supraclavicular flap: analysis of 103 flaps used to reconstruct neck scar contractures. Plastic and reconstructive surgery.123(5): 1471-1480.

6.Pallua N. and Noah E. M. (2000) The tunneled supraclavicular island flap: an optimized technique for head and neck reconstruction. Plastic and reconstructive surgery.105(3): 842-851.

7.Vũ Quang Vinh (2016), Nghiên cứu ứng dụng vạt da cân thượng đòn nối mạch vi phẫu tại đâu xa điều trị seo di chứng bỏng vùng cằm cổ, Đề tài cấp bộ Y tế.

8. Trần Vân Anh (2005), Nghiên cứu lâm sàng và điều trị sẹo di chứng bóng vùng cằm- cổ, Luận án tiến sỹ y học, Học viện Quân Y.

9. Trân thiết Sơn (2004), "Một số nhận xét về vạt da cân thượng đon áp dụng trong phấu thuật tạo hình ", TCNCYH 28 (2), tr.60-64

\title{
THỰC TRANG BỆNH SÂU RĂNG QUA KHÁM LÂM SÀNG VÀ ẢNH CHỰP BẰNG SMARTPHONE TRÊN SINH VIÊN NĂM THỨ NHẤT NGÀNH ĐIỀU DƯỠNG, TRƯỜ'NG CAO ĐẲNG Y TẾ HÀ ĐÔNG, NĂM HỌC 2019-2020
}

\author{
Mai Thị Giang Thanh ${ }^{1}$, Lê Thành Chung1, \\ Lê Thị Hương Giang ${ }^{2}$, Hoàng Bảo Duy ${ }^{3}$, Nguyễn Đức Thăng ${ }^{3}$
}

\section{TÓM TẮT}

Nghiên cứu mô tả cắt ngang nhằm mô tả tỷ lệ sâu răng hàm lớn vĩnh viến trên khám lâm sàng và ảnh chụp bằng smartphone, từ đó xác định độ nhạy và độ đặc hiệu qua ảnh chụp trên sinh viên nằm thứ nhất ngành điều dưỡng, trường Cao đẳng $\mathrm{Y}$ tế Hà Đông, năm hoc 2019-2020. Kết quả nghiên cứu cho thấy: Tý lệ sâu răng hàm lớn vĩnh viễn là $93,2 \%$ qua phương pháp khám lâm sàng và $72,8 \%$ qua phương pháp ảnh chụp. Độ nhạy, độ đặc hiệu chung cho tất cả các mă̆t răng lần lượt là $88,2 \%$ và $90,6 \%$. Tại mặt ngoài độ nhạy và độ đặc hiệu là $67,3 \%$ và $81,5 \%$. Mặt nhai có độ nhạy và̀ độ đặc hiệu là $83,3 \%$ và $84,5 \%$. Độ chính xác lớn hơn $80 \%$ ở cả mặt nhai, mặt ngoài và chung cho tất cả các măt răng.

Từ khoá: Sầu răng, khám lâm sàng, ảnh chụp smartphone, sinh viên nắm thứ nhất.

\footnotetext{
${ }^{1}$ Trường Cao đẳng Y tế Hà Đông

2Trường Cao đằng Y tế Hà Đông

${ }^{3}$ Trường Đại học Y Hà Nội

Chịu trách nhiệm chính: Mai Thị Giang Thanh

Email: maithigiangthanh@gmail.com

Ngày nhận bài: 23/2/2021

Ngày phản biện khoa học: 16/3/2021

ngày duyệt bài: 5/4/2021
}

SUMMARY

DENTAL CARIES DIAGNOSED THROUGH CLINICAL EXAMINATION AND PHOTOS TAKEN BY SMARTPHONES IN FIRST-YEAR NURSING STUDENTS, HA DONG MEDICAL COLLEGE, SCHOOL YEAR 2019-2020

The cross-sectional descriptive study aims to describe the rate of permanent molar caries on clinical examination and photos taken with smartphones. Thereby determining the sensitivity and specificity through photos taken on first-year nursing students, Ha Dong Medical College, academic year 2019-2020. The results show that: The rate of permanent molar caries is $93.2 \%$ by clinical examination method and $72.8 \%$ by imaging method. The general sensitivity and specificity for all tooth surfaces were $88.2 \%$ and $90.6 \%$, respectively. On the facial surface, these numbers were $67.3 \%$ and $81.5 \%$. The sensitivity and specificity of the chewing surface were $83.3 \%$ and $84.5 \%$. $80 \%$ greater accuracy in both occlusal surface, facial surface and common to all tooth surfaces.

Key words: Dental caries, clinical examination, photos taken with smartphone, first-year student.

\section{I. ĐẶT VẤN ĐỀ}

Bệnh sâu răng là một trong hai bệnh răng miệng phổ biến với tỷ lệ người mắc bệnh cao 